\title{
Curricula proposals aim to bolster scientific competency
}

$\mathrm{C}$ urrent undergraduate and medical school curricula fail to adequately prepare physicians "to actually use scientific knowledge" once in practice, a blue-ribbon committee of United States medical educators says.

Urging a major overhaul of both undergraduate premedical and medical school curricula so as to "reinvigorate the scientific preparation of physicians," an expert committee struck by the Association of American Medical Colleges - a not-for-profit association that represents all 130 US and 17 accredited Canadian medical schools - and the Howard Hughes Medical Institute says institutions should adopt pedagogical models that focus on the acquisition of a "dynamic set of competencies," rather than staid delivery of required courses.

Such an approach would ensure that doctors are ultimately able "to comprehend their own disciplinary literature and to evaluate critically claims of therapeutic effectiveness and safety throughout their active careers," the 22-member committee co-chaired by Yale University
School of Medicine Dean Dr. Robert J. Alpern and Stanford University Professor of Biological Sciences Sharon Long, stated in its final report, Scientific Foundations for Future Physicians.

Teaching competencies, which the committee defined as "the knowledge, skill or attitude that enables an individual to learn and perform in medical practice and to meet or exceed the standards of the profession," would result in doctors with more flexible minds. "Physicians should possess a deep understanding of the fundamental biomedical scientific principles needed to deal with the unexpected; they should not rely solely on algorithm-based practice."

"The desired outcome of the medical education process should be scientifically inquisitive and compassionate physicians who have the motivation, the tools and knowledge to find the necessary information to provide the best and most scientifically sound care for their patients," the report stated.

In many respects, the report is the byproduct of a broader American move

\section{Box 1: Required competencies for licensure}

The 8 competencies that a blue-ribbon committee struck by the Association of American Medical Colleges and the Howard Hughes Medical Institute recommends should be adopted for determining whether a medical student should be licensed are:

- "Apply knowledge of molecular, biochemical, cellular, and systems-level mechanisms that maintain homeostasis, and of the dysregulation of these mechanisms, to the prevention, diagnosis and management of disease.

- "Apply major principles of physics and chemistry to explain normal biology, the pathobiology of significant diseases, and the mechanism of action of major technologies used in the prevention, diagnosis and treatment of disease.

- "Use the principles of genetic transmission, molecular biology of the human genome, and population genetics to infer and calculate risk of disease, to institute an action plan to mitigate this risk, to obtain and interpret family history and ancestry data, to order genetic tests, to guide therapeutic decision making and to assess patient risk.

- "Apply the principles of the cellular and molecular basis of immune and nonimmune host defence mechanisms in health and disease to determine the etiology of disease, identify preventive measures and predict response to therapies.

- "Apply the mechanisms of general and disease-specific pathological processes in health and disease to the prevention, diagnosis, management and prognosis of critical human disorders.

- "Apply principles of the biology of microorganisms in normal physiology and disease to explain the etiology of disease, identify preventive measures and predict response to therapies.

- "Apply the principles of pharmacology to evaluate options for safe, rational and optimally beneficial drug therapy.

- "Apply quantitative knowledge and reasoning - including integration of data, modelling, computation, and analysis - and informatics tools to diagnostic and therapeutic clinical decision making."

toward competency-based education, licensure and recertification of physicians that is being mirrored in Canada by the Royal College of Physicians and Surgeons of Canada through its Canadian Medical Education Directors for Specialists project, and in an ongoing review of medical education by the Association of Faculties of Medicine of Canada.

President and Chief Executive Officer Dr. Nick Busing says that the Future of Medical Education in Canada project, slated for completion this fall, will include a recommendation urging more effective integration of scientific competency into medical education.

"Given that medicine is rooted in fundamental scientific principles, basic sciences, both human and biological, should be taught, learned and assessed in relevant and immediate clinical context throughout the undergraduate experience," said Busing.

"The thrust of this recommendation is to emphasize the scientific basis of medicine, number one," Busing adds. "Secondly, to be sure that we consider science as both the human sciences and the biological sciences and 3, to teach science and educate students by integrating the scientific base of medicine throughout the 4 years, rather than, for instance, just focusing on it in the first couple of years and then focusing strictly on the clinical experience."

Such a competency-based approach should extend to both undergraduate premedical education, as well as medical education, to ensure more "flexibility in the training environment," Busing says.

"We want it to be competency-based and flexible, so that, for instance, we can encourage students to become clinicianscientists and pursue scholarly study related to becoming a scientist. Or it may that the students want to be able to develop competencies in business and so the concept of an MD with an MBA as part of an integrated program needs to be considered."

Association of American Colleges Executive Vice-President Dr. Carol Aschenbrener says there have been a number of drivers for change in the US, including a widespread perception that premedical education requirements are 


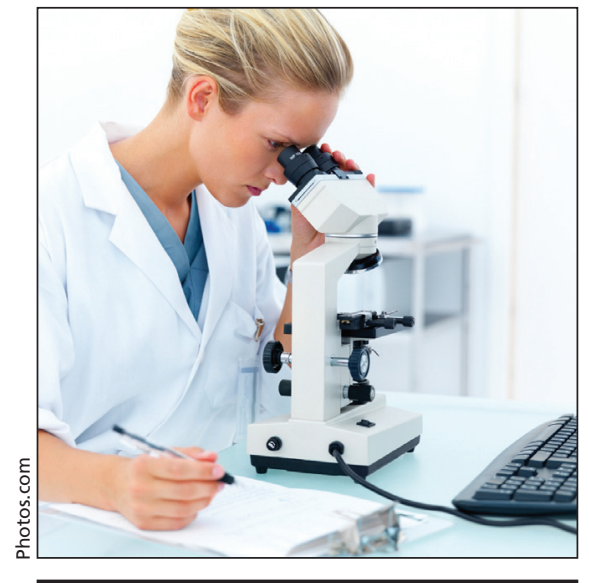

Medical educators want future physicians to have a deeper understanding of fundamental scientific principles.

too constrictive and that the medical school admission process is outdated, having been unchanged in over 40 years.

"A number of undergraduate institutions perceive that premed requirements are a constraint on their ability to devise more flexible" and interdisciplinary criteria, she says.

As well, there is a broad move within medicine toward competency-based approaches to licensure exams and physician recertification, Aschenbrener adds, noting that the American Board of Medical Specialties is now committed to adopting "competence for maintenance of specialty certification and also for maintenance of licensure," by 2011.
The US expert committee recommended that medical students should demonstrate 8 competencies in the natural sciences before being granted an MD (Box 1). Similarly, it recommended that medical schools adopt selection processes that are aimed at ascertaining whether prospective students have demonstrated 8 specific competencies (Box 2). To that end, the Association of American Medical Colleges says it will assess the committee's recommendations in the context of its ongoing review of the Medical College Admission Test, which will be completed by 2012 .

The committee also stressed that its intention is not to increase the number of requirements within medical school curriculum, or for medical school admission, but rather to promote "substitution of more relevant requirements for some that are less relevant." In most institutions, existing courses that meet the recommendations for premedical study, plus added learning experiences — for example, in statistics — can be used to prepare students to meet the recommended competencies. However, the committee strongly encourages the design of new curricula that would create synergies and exciting new learning experiences, and foster partnerships across disciplines."

Aschenbrener says US medical schools have already started moving

\section{Box 2: Required competencies for medical school admission}

The 8 competencies that a blue-ribbon committee of the Association of American Medical Colleges and the Howard Hughes Medical Institute recommends should be adopted for determining whether a student be admitted to medical school are:

- "Apply quantitative reasoning and appropriate mathematics to describe or explain phenomena in the real world.

- "Demonstrate understanding of the process of scientific inquiry, and explain how scientific knowledge is discovered and validated.

- "Demonstrate knowledge of basic physical principles and their applications to the understanding of living systems.

- "Demonstrate knowledge of basic principles of chemistry and some of their applications to the understanding of living systems.

- "Demonstrate knowledge of how biomolecules contribute to the structure and function of cells.

- "Apply understanding of principles of how molecular and cell assemblies, organs and organisms develop structure and carry out function.

- "Explain how organisms sense and control their internal environment and how they respond to external change.

- "Demonstrate an understanding of how the organizing principle of evolution by natural selection explains the diversity of life on earth." 
toward "some sort of framework that is focused more on the broad competencies. Various schools are trying to do that more specifically in the clinical courses. There's been much less movement toward competencies in the basic science courses."

Busing says several Canadian medical schools are also "developing more and more of their objectives in a competency-based manner," although he projects what will ultimately emerge is a "combination" of competency-based and traditional curricula.

A similar standard appears to be the target for medical school admissions. Busing says the ongoing review of medical education will likely include a recommendation that "encourages the diversity of the Canadian population to apply [and] emphasizes the importance of academic standing and rigour." But admission won't rest solely on academic scores; they will also look for candidates with good communication, collaboration and interpersonal skills. "Some of these other qualities are, in our opinion, key attributes of the physicians of the future."

Both Aschenbrener and Busing stress that the competency-based approaches are not prescriptive, but rather a blueprint by which schools can develop new courses that are more "interdisciplinary" and "integrative."

Medical schools can't be forced into anything, Aschenbrener notes. "But what I would say is that with the knowledge explosion that we have, the priority has to be to equip physicians to be skillful learners and motivated learners throughout their professional lifetime. You can't give them everything they need for a lifetime in medical school and residency. So they have to be at a point that they understand the concepts, they have the tools to self-assess, to learn on their own and to integrate new behaviour. And the notion of competencies is focusing on the knowledge skills and attitudes that one uses regularly in your medical practice."

Busing says that the Canadian review will seek a similar collegial shift within Canadian medical schools and to that end, the final report is "being entitled A Collective Vision, because we really want it to be a vision for the future, but not prescriptive, that says you have to institute recommendations 1-10 in the way they are." - Wayne Kondro, CMAJ

DOI:10.1503/cmaj.091197

\section{British Medical Association pitches for end to management speak, urges use of plain language}

$\mathrm{T}$ he message was blunt: Enough of the performer-service user relationship.

The British Medical Association has urged the United Kingdom's National Health Service to ditch its management-speak and begin using clearer language, for example, "patient" rather than "client" or "service user."

A motion passed unanimously at the British Medical Association's Consultants Conference on June 3 called on the National Health Service to use plain English, starting with references to a patient, which in common parlance, describes "the person in the partnership between doctors and those who consult them for health care advice or with an illness."

There's been an inexorable move toward management-speak at the National Health Service in recent years, says Dr. Peter Bamber, the West Yorkshire anesthetist who sponsored the motion. "But what really got me going was an internal document which I couldn't at first understand. It took

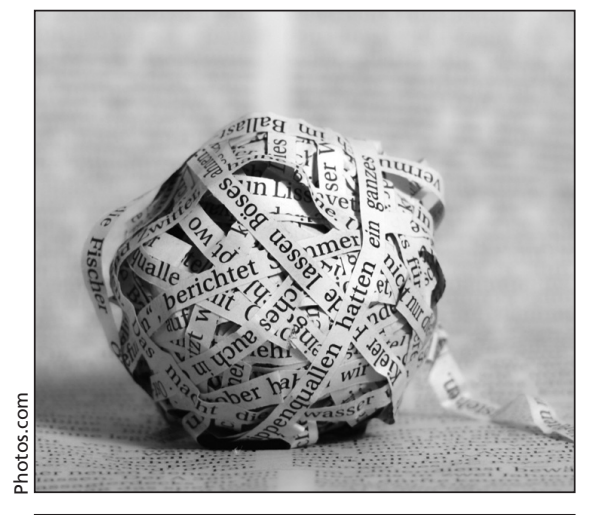

British doctors say the line between gobbledygook and plain English has long since been crossed by the UK's National Health Service.

me several minutes before I realized it was about psychiatric patients and required a response from me. It would have been all too easy just to hit the 'delete' button."

Bamber speculates that referring to patients as "service users" was an attempt to destigmatize illness.

"But if you're ill, you deserve sym- pathy and 'patient' is a word that generates sympathy," he says.

Other examples of jargon in National Health Service documents include the term "performer" for doctor, "efficiency savings and disinvestments" for budget cuts, and a request for volunteers to take part in a "proof of concept" project rather than a pilot project. Some National Health Service patients have received letters informing them that their treatment was "embedded within an indication of needs matrix."

The issue has also drawn the attention of the Plain English Campaign, a UK-based group promoting the use of clear language in public communication, which noted that language confusion among doctors and patients could well become a life or death issue.

While some National Health Service hospitals and trusts have received the Plain English Campaign's annual Crystal Mark for clarity of language, other health institutions have received its notorious Golden Bull award. Last year, the National Health Service 